\title{
Start and turn performances of elite sprinters at the 2016 European Championships in swimming
}

\author{
Jorge E. Morais, Daniel A. Marinho, Raul Arellano \& Tiago M. Barbosa
}

To cite this article: Jorge E. Morais, Daniel A. Marinho, Raul Arellano \& Tiago M. Barbosa (2018): Start and turn performances of elite sprinters at the 2016 European Championships in swimming, Sports Biomechanics, DOI: 10.1080/14763141.2018.1435713

To link to this article: https://doi.org/10.1080/14763141.2018.1435713

\section{Published online: 26 Mar 2018.}

Submit your article to this journal

Q View related articles $₫$

View Crossmark data $\nearrow$ 


\title{
Start and turn performances of elite sprinters at the 2016 European Championships in swimming
}

\author{
Jorge E. Morais ${ }^{a, d}$, Daniel A. Marinho ${ }^{a, d}$, Raul Arellano and Tiago M. Barbosa ${ }^{b, c, d}$ \\ aDepartment of Sport Sciences, Faculty of Social and Human Sciences, University of Beira Interior, Covilhã, \\ Portugal; 'bepartment of Sport Sciences, Superior School of Education, Polytechnic Institute of Bragança, \\ Bragança, Portugal; ' National Institute of Education, Nanyang Technological University, Singapore, Singapore; \\ ${ }^{\mathrm{d}}$ Research Centre in Sports, Health and Human Development, University of Trás-os-Montes and Alto Douro, \\ Vila Real, Portugal; 'Department of Physical and Sports Education, University of Granada, Granada, Spain
}

\begin{abstract}
The aim of this study was to examine the performance characteristics of male and female finalists in the 100-m distance at the 2016 European Championships in swimming (long-course-metre). The performances of all 64 (32-males and 32-females) were analysed (8 swimmers per event; Freestyle, Backstroke, Breaststroke and Butterfly). A set of start and turn parameters were analysed. In the start main outcome, male swimmers were faster in Butterfly $(5.71 \pm 0.14 \mathrm{~s})$ and females in Freestyle $(6.68 \pm 0.28 \mathrm{~s})$. In the turn main outcome, male and female swimmers were faster in Freestyle (males: $9.55 \pm 0.13 \mathrm{~s}$; females: $10.78 \pm 0.28 \mathrm{~s}$ ). A significant and strong stroke effect was noted in the start and turn main outcome, in both sexes. In the start plus the turn combined, males and females were faster in Freestyle (males: $15.40 \pm 0.20$ s; females: $17.45 \pm 0.54 \mathrm{~s}$ ). The start and the turn combined accounted almost one-third of the total race time in all events, and non-significant differences $(p>0.05)$ were noted across the four swim strokes. Once this research made evident the high relevance of start and turns, it is suggested that coaches and swimmers should dedicate an expressive portion of the training perfecting these actions.
\end{abstract}

\section{ARTICLE HISTORY}

Received 8 June 2017

Accepted 25 January 2018

\section{KEYWORDS}

Kinematics; technique; performance analysis; race

\section{Introduction}

Olympic and World records are broken on regular basis in competitive swimming. Literature notes that performance enhancement in elite swimmers is multifactorial (Barbosa, Bragada, Reis, Marinho, \& Silva, 2010). The planning and execution of an appropriate race strategy is one of those key-factors and considered as paramount to excel in competitive swimming (Arellano, Brown, Cappaert, \& Nelson, 1994).

The swim race can be split-up into several components or phases: the start, the clean swimming (or swim stroke), the turn(s) and the finish. The swimming speed is determined by the stroke length and stroke rate (Craig \& Pendergast, 1979). Over the last few 
decades, the swim stroke profile of elite swimmers at major competitions, such as World Championships and Olympic Games, have been reported (e.g., Arellano et al., 1994; Hellard et al., 2008; Jesus et al., 2011; Wakayoshi, Nomura, Takahashi, Mutoh, \& Miyashita, 1992). Overall, researchers had a strong interest on the swim stroke, disregarding the acyclic phases of the race (i.e., the start and the turn). Albeit, studies can be found about such topic (e.g., Mason \& Cossor, 2001; Pereira et al., 2015; Vantorre, Seifert, Fernandes, Vilas-Boas, \& Chollet, 2010; Veiga \& Roig, 2016; Veiga, Roig, \& Gómez-Ruano, 2016). However, there is no evidence about how elite swimmers behave in major competitions in all four strokes. In short-distance events (i.e., sprinting), the start and turn(s) account for a significant proportion of time and distance, e.g., in a 100-m sprint the swimmer might spend a total of 40-m in the start, turn and finish (e.g., Cossor \& Mason, 2001; Mason \& Cossor, 2001). Nevertheless, one may argue that the last 5 -m of each lap can also be considered as part of the clean swim segment of the race, reducing that length to no more than $30-\mathrm{m}$. In middleand long-distance events, the addition of trivial enhancements in each turn can account for a significant improvement in the final race time. For instance, in the long course $800-\mathrm{m}$ Freestyle event the swimmer performs 15 turns. If this swimmer improves just $0.1 \mathrm{~s}$ in each turn, this accounts for an overall improvement of $1.5 \mathrm{~s}$ in the final race time.

Studies have pointed out the key-determinants of the start (Arellano, García, Gavilán, \& Pardillo, 1996; Blanksby, Nicholson, \& Elliott, 2002; Tor, Pease, \& Ball, 2015; Vantorre et al., 2010) and turn (Lyttle, Blanksby, Elliott, \& Lloyd, 1999; Veiga \& Roig, 2016). The split time at the 15-m mark is significantly associated to the start performance (Cossor \& Mason, 2001). Moreover, it was reported that the start performance should rely on the optimisation of the underwater phase (i.e., gliding, dolphin kicks and water breakout) before starting the swim stroke (e.g., Cossor \& Mason, 2001; Guimarães \& Hay, 1985). The body of knowledge on turning is also rather scarce, when comparing to the swim stroke (e.g., Mason \& Cossor, 2001; Pereira et al., 2015; Slawson, Conway, Jusham, Le Sage, \& West, 2010; Veiga \& Roig, 2016, 2017). A study conducted by Mason and Cossor (2001) concluded that the fastest swimmers were not the fastest turners. A non-significant relationship was noted between the pre-turn swim velocity and the turn velocity, suggesting that swim stroke and turning performances are not related. It was also noted that the push-off and underwater phase were the most determinant moments of the turn performance (Mason \& Cossor, 2001). This emphasises the need of specific training sets to improve the turning performance. Recently, Veiga \& Roig (2016) pointed out that coaches and swimmers should prepare a race strategy, for the turn(s), based on the underwater performance of each swimmer, since they are strongly related (the turn and the underwater performance).

To the best of our knowledge, a comparison of the start and turning performances between the four swimming strokes, in major competition events, in both sexes is also very limited. Only few studies can be found in the literature, assessing the start (e.g., Arellano et al., 1994; Cossor \& Mason, 2001; Veiga \& Roig, 2017), and the turn (e.g., Arellano et al., 1994; Mason \& Cossor, 2001; Veiga \& Roig, 2016; Veiga et al., 2016). Besides that, only few provide information about what happens in intermediate stages of the total start and turn (as the underwater time and distance) (e.g., Tor et al., 2015; Veiga \& Roig, 2016; Veiga et al., 2016). This information might be important in understanding how swimmers can improve their total start and turn time. Moreover, there have been only a few studies reporting the contribution of the start and turn performances to the final race time (e.g., Arellano et al., 1994; Cossor \& Mason, 2001; Tor et al., 2015). In this sense, there is an increasing interest 
in understanding how starts and turns can help enhancing the performance, and how these moments can affect the overall race strategy (e.g., Tor et al., 2015; Veiga \& Roig, 2017).

The aims of this study were to: (i) examine the start and turn performances of male and female elite sprinting swimmers (racing the final of the 100-m events at a major swimming competition) and; (ii) compute the partial contribution of the start and turn to the final race time It was hypothesised that: (i) a stroke effect would be verified (i.e., significant variations should be found between swimming strokes in each sex) and; (ii) the start and turn show meaningful contributions to the final race time.

\section{Methods}

\section{Participants}

The performances of all 64 ( 32 males and 32 females) finalists in the 100-m events at the 2016 long course metre LEN European Aquatic Championships, held in London, were analysed (8 swimmers per event; Freestyle, Backstroke, Breaststroke and Butterfly; males and females).

\section{Data collection}

The official race times (final race time of the 100 -m event, 50-m split time and reaction/block time) were retrieved from the competition official website (www.london2016.microplustiming.com).

The championships organisation provided the recordings of all races in high-definition (HD) video $(f=50 \mathrm{~Hz})$. The system delivered real-time multi-angle recordings. A set of 10 pan-tilt-zoom cameras tracked the swimmers, one camera for each lane (AXIS v5915, Lund, Sweden). Each swimmer was recorded by one of these cameras. Two fixed cameras (AXIS q1635, Lund, Sweden) recorded both ends of the swimming pool, enabling the analysis of the start and turn. The official timer was synchronised with starting lights that were visible by all cameras. The starting light was used as reference to set the time-stamp on the race analysis software. The videos were analysed by one expert evaluator, on an in-house customised software for race analysis in competitive swimming. The Intra-class Correlation Coefficient (ICC) was computed to verify the absolute agreement between repeated measures. A veryhigh agreement was obtained (ICC ranged between 0.989 and 0.999 ).

\section{Starting parameters}

The following parameters were measured: (i) 15-m mark time (i.e., start main outcome: the time lag between the starting signal and the 15-m mark); (ii) reaction time or block time (the time lag between the signal and the instant the swimmer's feet left the block). This parameter was retrieved from the championship official website (www.london2016. microplustiming.com); (iii) entry time (the time lag between the start signal and the hands' contacting with water); (iv) flight time (the time lag between the instant the toes left the block and the hands' entry); (v) entry distance (the distance between the starting wall and the hands' entry); (vi) underwater time (the time lag between the hands' entry and the water break by the head); (vii) underwater distance (the distance between the hands' entry and the water break by the head); (viii) break time (the time lag between the start signal and the 
head breaking out the water surface); (ix) break distance (the distance between the starting head-wall and the head water breakout). All distances were calibrated based on the pool's marks (e.g., the 5-m and 15-m marks of the swim lanes). The parameters selected are often reported in the literature (e.g., Hubert, Silveira, Freitas, Pereira, \& Roesler, 2006; Ruschel, Araùjo, Pereira, \& Roesler, 2007; Vantorre et al., 2010).

\section{Turning parameters}

The following variables were measured: (i) total turning time (i.e., turn main outcome: the time lag between the $45-\mathrm{m}$ mark and the 15 - $\mathrm{m}$ mark of the following split); (ii) the $5 \mathrm{~m}$-in time (the time lag between the 45-m mark and the touch on the wall); (iii) water break distance (the distance between the wall and the head breaking out the water surface); (iv) water break time (the time lag between the touch on the wall and the head water break); (v) 15 - $\mathrm{m}$ out time (the time lag between the touch on the wall and the 15-m mark). All distances were calibrated based on the pool's marks (e.g., the 5-m and 15-m marks of the swim lanes). These turning variables, are also noted by the literature on regular basis (Blanksby, Simpson, Elliott, \& McElroy, 1998; Lyttle, Blanksby, Elliott, \& Lloyd, 2000; Veiga \& Roig, 2017).

\section{Statistical analysis}

Normality and homocedasticity assumptions were analysed by the Kolmogorov-Smirnov and Levene tests, respectively. The mean \pm one standard deviation (SD), and the $95 \%$ of the confidence interval (95CI) were selected as descriptive statistics.

The stroke effect (i.e., variation in the performance of the start and turn across the four swimming events, in each sex), and the partial contribution effect (i.e., variation in the contribution of each start and turn parameter assessed to the final race time) were computed by one-way ANOVAs, and Bonferroni as post-hoc test $(p \leq 0.05)$. The eta square $\left(\eta^{2}\right)$ was selected as effect size index and interpreted as: (i) without effect if $0<\eta^{2}$ $\leq 0.04$; (ii) minimum/trivial if $0.04<\eta^{2} \leq 0.25$; (iii) moderate if $0.25<\eta^{2} \leq 0.64$ and; (iv) strong if $\eta^{2>} 0.64$ (Ferguson, 2009). Cohen's $d$ was also computed to assess the standard effect size in pairwise strokes, and interpreted as: (i) small/trivial if $d \leq 0.2$; (ii) moderate if $0.8 \geq d \geq 0.2$ and; (iii) large if $d \geq 0.8$ (Cohen, 1988).

\section{Results}

\section{Final race time}

A significant and strong stroke effect was noted in the final race time in both sexes (males: $F=540.35, p<0.001, \eta^{2}=0.98$; females: $F=235.51, p<0.001, \eta^{2}=0.96$ ) (Tables 1 and 3). Both sexes were faster in Freestyle, followed-up by Butterfly, Backstroke and Breaststroke (Table 1). The pairwise comparison showed significant differences $(p \leq 0.001)$ between all swimming strokes, in both sexes. The highest difference was noted between Freestyle and Breaststroke in male and female swimmers (males: $d=16.91, p<0.001$; females: $d=13.20$, $p<0.001)$. The lowest was observed between Backstroke and Butterfly, also in both sexes (males: $d=4.88, p<0.001$; females: $d=2.06, p=0.001$ ). 


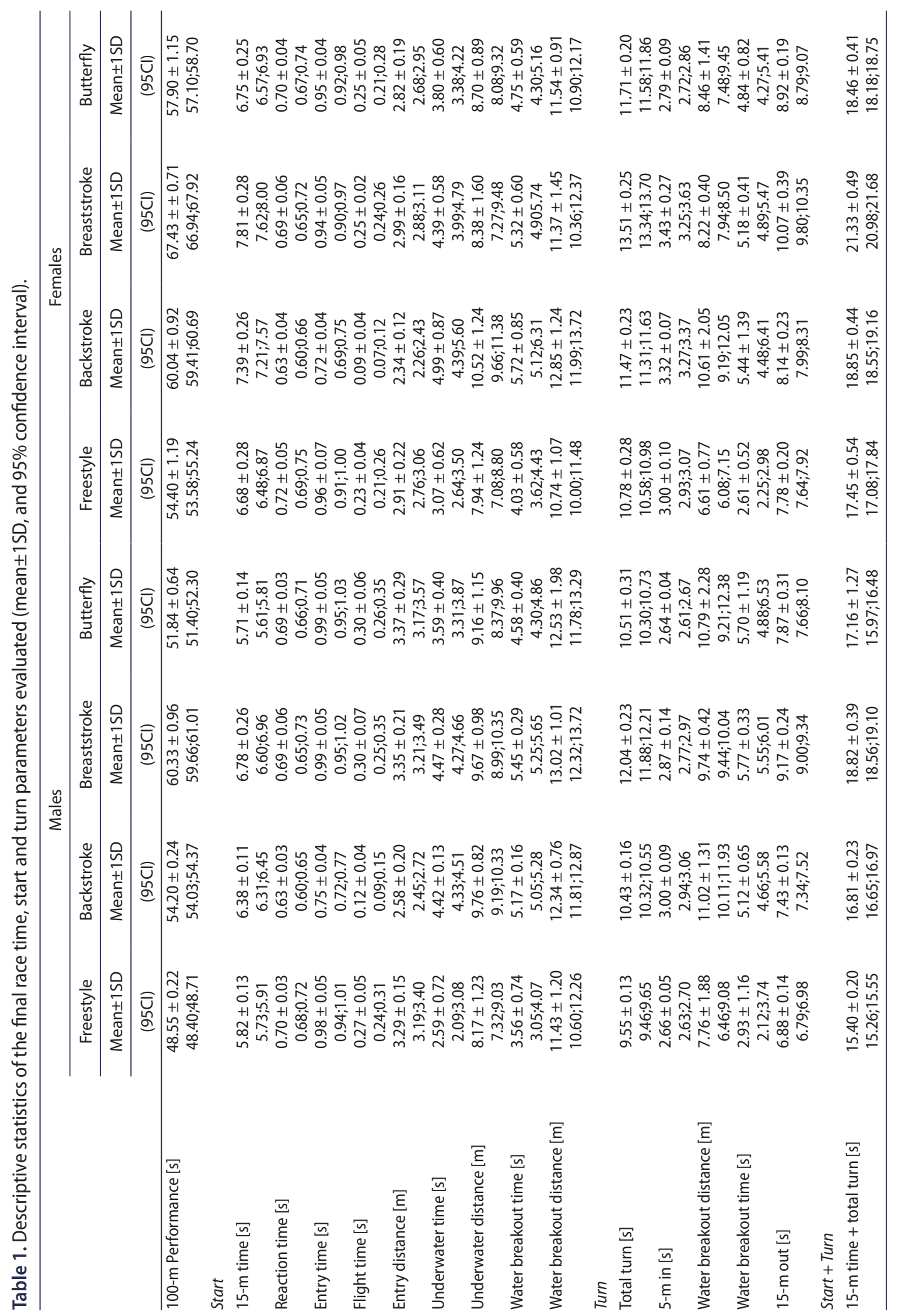




\section{Starting performance}

The 15-m time (the main outcome) showed a significant and strong stroke effect in male and female swimmers (males: $F=65.18, p<0.001, \eta^{2}=0.88$; females: $F=32.57, p<0.001$, $\eta^{2}=0.77$ ) (Table 3 ). A non-significant difference was observed only between Freestyle and Butterfly in both sexes $(p=1.000)$ (Table 3). Male swimmers spent less time covering the $15-\mathrm{m}$ in Butterfly, and females spent less time covering the 15- $\mathrm{m}$ in Freestyle (Table 1). The 15-m time showed a significant and moderate contribution effect in males $(F=15.57$, $\left.p<0.001, \eta^{2}=0.64\right)$, and females $\left(F=10.67, p<0.001, \eta^{2}=0.53\right)$ (Table 4). The partial contribution for the final race time, was higher in the Freestyle event for male finalists (11.96 $\pm 0.26 \%, 95 \mathrm{CI}: 11.75 ; 12.17)$, and in Backstroke for female counterparts $(12.31 \%$, 95CI: 12.01;12.60) (Table 2).

For males, the remaining starting variables presented significant and moderate-strong stroke effects (Table 3: $2.99 \leq F \leq 43.39 ; 0.04 \leq p<0.001 ; 0.25 \leq \eta^{2} \leq 0.82$ ). The block time, entry time, flight time and entry distance differ significantly $(p<0.05)$ between Backstroke and all of the remaining ones. Non-significant differences were observed between the remaining swimming strokes, in these parameters (Table 3 ). The underwater distance, and the water breakout distance also did not present significant differences (Table 3). On the other hand, the underwater time, and the water breakout time presented significant differences between them (underwater time: $2.72 \leq d \leq 3.44,0.005 \leq p<0.001$; water breakout time: $2.44 \leq d \leq 3.36,0.004 \leq p<0.001)$.

Regarding the stroke effect, females also showed variations in all parameters except in the water breakout distance (Table $3: F=2.38 ; p=0.117 ; \eta^{2}=0.35$ ). Pairwise comparisons returned non-significant differences $(p>0.05)$ in the block time, underwater time, water breakout time (except Backstroke vs. Butterfly and Freestyle, and Breaststroke vs. Freestyle), and water breakout distance. Significant differences were found for entry time (4.20 $\leq d \leq 4.85, p<0.001)$, flight time $(3.50 \leq d \leq 3.53, p<0.001)$, and entry distance $(2.91 \leq d \leq 4.59, p<0.001)$.

\section{Turning performance}

The total turn (the main outcome) showed a significant and strong stroke effect in males $\left(F=172.33, p<0.001, \eta^{2}=0.94\right)$ and females $\left(F=175.89, p<0.001, \eta^{2}=0.94\right)$ (Table $3)$. Pairwise comparison showed that the only exception (no differences) was between Backstroke and Butterfly, in both sexes (Table 3). Both male and female swimmers were faster performing the total turn in Freestyle (males: $9.55 \pm 0.13 \mathrm{~s}$; 95CI: 9.65; 9.46; females: $10.78 \pm 0.28$ s; 95CI: $10.98 ; 10.58$ ) (Table 1 ). The contribution effect was significant and moderate in males $\left(F=15.66, p<0.001, \eta^{2}=0.62\right)$, and significant and strong in females $\left(F=33.70, p<0.001, \eta^{2}=0.78\right)$ (Table 4$)$. The total turn showed a higher partial contribution in the Butterfly event in both sexes (males: $20.27 \pm 0.47 \%$, 95CI: 19.87; 20.70; females: $20.22 \pm 0.25 \%$, 95CI: 19.99;20.48).

For remaining parameters, the event swam showed a significant and moderate-strong effect for both males $\left(6.59 \leq F \leq 153.62 ; 0.002 \leq p<0.001 ; 0.41 \leq \eta^{2} \leq 0.94\right)$ and females $\left(12.35 \leq F \leq 112.70 ; p<0.001 ; 0.56 \leq \eta^{2} \leq 0.92\right)$ (Table 3). Overall, male swimmers presented significant differences in the $15-\mathrm{m}$ out $(1.84 \leq d \leq 11.25,0.003 \leq p<0.001)$, and $5-\mathrm{m}$ in $(1.85 \leq d \leq 5.16, p \leq 0.001)$. Non-significant differences were found in the water breakout 


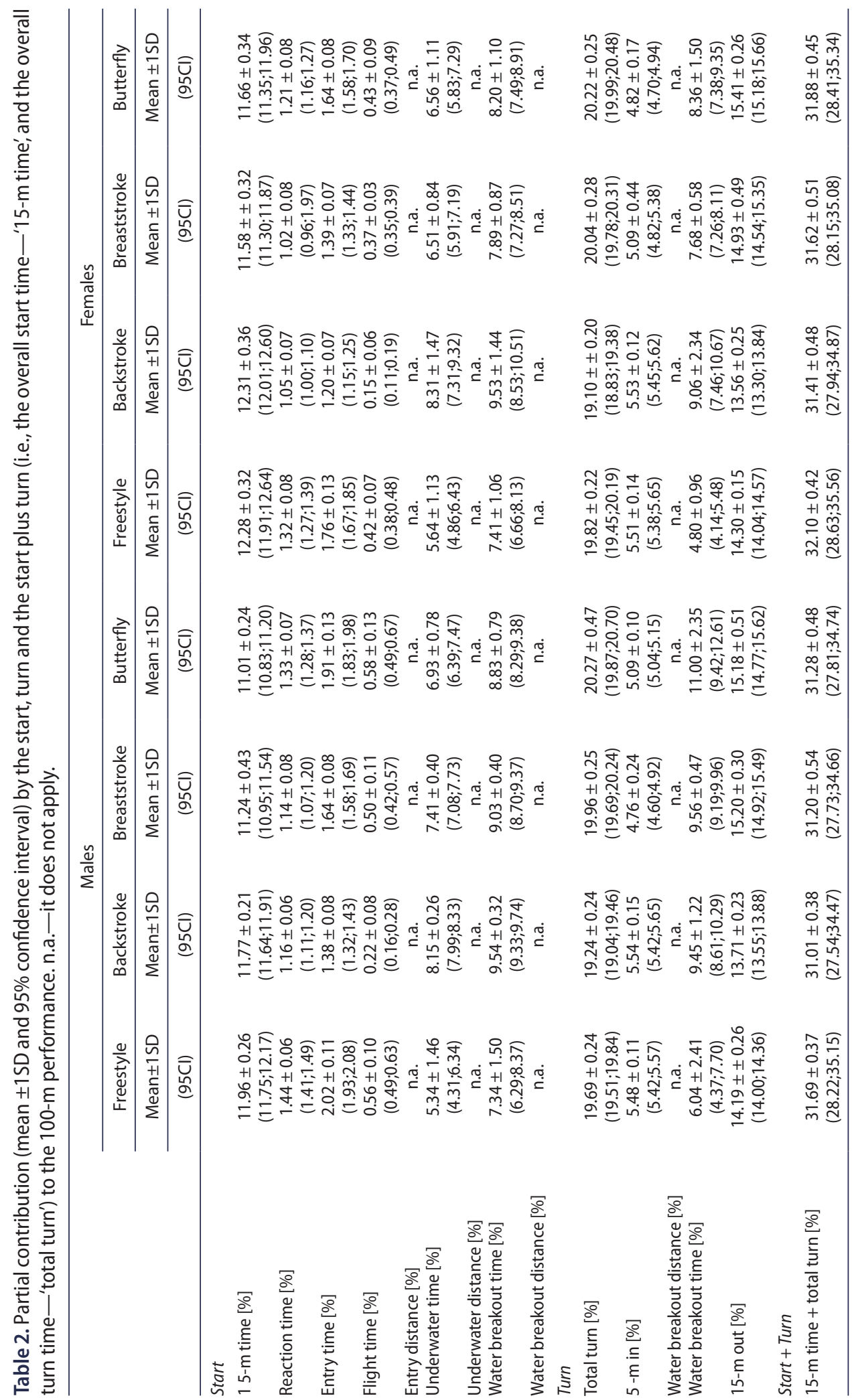


Table 3. Analysis of the stroke effect in males and females finalists.

\begin{tabular}{|c|c|c|c|c|c|c|c|c|}
\hline & \multicolumn{4}{|c|}{ Males } & \multicolumn{4}{|c|}{ Females } \\
\hline & $F$ & $p$ & $\eta^{2}$ & Pairwise & $F$ & $p$ & $\eta^{2}$ & Pairwise \\
\hline $\begin{array}{l}\text { 100-m Perfor- } \\
\text { mance [s] }\end{array}$ & 540.35 & $<0.001$ & 0.98 & * & 235.51 & $<0.001$ & 0.96 & * \\
\hline \multicolumn{9}{|l|}{ Start } \\
\hline 15-m time $[\mathrm{s}]$ & 65.18 & $<0.001$ & 0.88 & $\begin{array}{l}\text { * (except Free } \\
\text { vs Fly) }\end{array}$ & 32.57 & $<0.001$ & 0.77 & $\begin{array}{l}\text { * (except Free vs } \\
\text { Fly) }\end{array}$ \\
\hline $\begin{array}{l}\text { Reaction time } \\
{[\mathrm{s}]}\end{array}$ & 5.60 & 0.004 & 0.37 & $\begin{array}{l}\text { \# (except Back } \\
\text { with all) }\end{array}$ & 5.33 & 0.005 & 0.36 & $\begin{array}{l}\text { \# (except Back vs } \\
\text { Fly, Back vs Free) }\end{array}$ \\
\hline Entry time [s] & 43.39 & $<0.001$ & 0.82 & $\begin{array}{l}\text { \# (except Back } \\
\text { with all) }\end{array}$ & 34.70 & $<0.001$ & 0.78 & $\begin{array}{l}\text { * (except Free vs } \\
\text { Breast, Fly vs } \\
\text { Breast, Fly vs Free }\end{array}$ \\
\hline Flight time $[\mathrm{s}]$ & 18.35 & $<0.001$ & 0.66 & $\begin{array}{l}\text { \# (except Back } \\
\text { with all) }\end{array}$ & 31.82 & $<0.001$ & 0.77 & $\begin{array}{l}\text { * (except Free vs } \\
\text { Breast, Fly vs } \\
\text { Breast, Fly vs Free }\end{array}$ \\
\hline $\begin{array}{l}\text { Entry distance } \\
\quad[\mathrm{m}]\end{array}$ & 24.32 & $<0.001$ & 0.72 & $\begin{array}{l}\text { \# (except Back } \\
\text { with all) }\end{array}$ & 21.21 & $<0.001$ & 0.69 & $\begin{array}{l}\text { * (except Free vs } \\
\text { Breast, Fly vs } \\
\text { Breast, Fly vs Free }\end{array}$ \\
\hline $\begin{array}{l}\text { Underwater } \\
\text { time }[\mathrm{s}]\end{array}$ & 32.28 & $<0.001$ & 0.77 & $\begin{array}{l}\text { * (except Back vs } \\
\text { Breast) }\end{array}$ & 11.69 & $<0.001$ & 0.55 & $\begin{array}{l}\text { \# (except Back vs } \\
\text { Fly, Back vs Free, } \\
\text { Breast vs Free) }\end{array}$ \\
\hline $\begin{array}{l}\text { Underwater } \\
\text { distance [m] }\end{array}$ & 3.44 & 0.031 & 0.28 & $\begin{array}{l}\text { \# (except Back vs } \\
\text { Free) }\end{array}$ & 3.65 & 0.043 & 0.45 & $\#$ \\
\hline $\begin{array}{l}\text { Water breakout } \\
\text { time }[s]\end{array}$ & 27.27 & $<0.001$ & 0.74 & $\begin{array}{l}\text { * (except Back } \\
\text { vs Breast, Back } \\
\text { vs Fly) }\end{array}$ & 9.70 & $<0.001$ & 0.50 & $\begin{array}{l}\text { \# (except Back vs } \\
\text { Free, Back vs Fly, } \\
\text { Breast vs Free) }\end{array}$ \\
\hline $\begin{array}{l}\text { Water breakout } \\
\text { distance }[\mathrm{m}]\end{array}$ & 2.99 & 0.043 & 0.25 & $\begin{array}{l}\text { \# (except Breast } \\
\text { vs Free) }\end{array}$ & 2.38 & 0.117 & 0.35 & $\#$ \\
\hline \multicolumn{9}{|l|}{ Turn } \\
\hline Total turn [s] & 172.33 & $<0.001$ & 0.94 & $\begin{array}{l}\text { * (except Back } \\
\text { vs Fly) }\end{array}$ & 175.89 & $<0.001$ & 0.94 & $\begin{array}{l}\text { * (except Back vs } \\
\text { Fly) }\end{array}$ \\
\hline $5-\mathrm{m}$ in $[\mathrm{s}]$ & 27.94 & $<0.001$ & 0.75 & $\begin{array}{l}\text { * (except Back } \\
\text { vs Breast, Free } \\
\text { vs Fly) }\end{array}$ & 27.82 & $<0.001$ & 0.74 & $\begin{array}{l}\text { * (except Back vs } \\
\text { Breast, Free vs } \\
\text { Fly) }\end{array}$ \\
\hline $\begin{array}{l}\text { Water breakout } \\
\text { distance }[\mathrm{m}]\end{array}$ & 6.59 & 0.002 & 0.41 & $\begin{array}{l}\text { \# (except Back vs } \\
\text { Free, Fly vs Free }\end{array}$ & 12.35 & $<0.001$ & 0.56 & $\begin{array}{l}\text { * (except Breast } \\
\text { vs Fly, Free vs } \\
\text { Breast) }\end{array}$ \\
\hline $\begin{array}{l}\text { Water breakout } \\
\text { time }[s]\end{array}$ & 17.12 & $<0.001$ & 0.64 & $\begin{array}{l}\text { \# (except Back } \\
\text { vs Free, Breast } \\
\text { vs Free, Fly vs } \\
\text { Free) }\end{array}$ & 17.44 & $<0.001$ & 0.65 & $\begin{array}{l}\text { \# (except Free with } \\
\text { all) }\end{array}$ \\
\hline $15-m$ out $[s]$ & 153.62 & $<0.001$ & 0.94 & * & 112.70 & $<0.001$ & 0.92 & $\begin{array}{l}\text { * (except Back vs } \\
\text { Free) }\end{array}$ \\
\hline \multicolumn{9}{|l|}{ Start + Turn } \\
\hline $\begin{array}{l}\text { 15-m time }+ \\
\text { total turn }[\mathrm{s}]\end{array}$ & 155.82 & $<0.001$ & 0.94 & * & 94.32 & $<0.001$ & 0.90 & $\begin{array}{l}\text { * (except Back vs } \\
\text { Fly) }\end{array}$ \\
\hline
\end{tabular}

Notes: Free-Freestyle; Fly—Butterfly; Back—Backstroke; Breast—Breaststroke.

* _ significant differences between all four swimming strokes $(p<0.05)$; \#-non-significant differences between all four swimming strokes $(p \geq 0.05)$.

distance, and in the water breakout time (with few exceptions between events; Table 3). Overall, female swimmers did show significant differences in the 15-m out between events $(3.61 \leq d \leq 7.19, p<0.001)$, except in Freestyle vs. Backstroke. Same trend was noted in remaining turning parameters, and non-significant differences were only observed in the water breakout time (Table 3 ). 
Table 4. Analysis of the partial contribution effect, by the start and turn to the 100 -m final race time, in males and females finalists.

\begin{tabular}{|c|c|c|c|c|c|c|c|c|}
\hline & \multicolumn{4}{|c|}{ Males } & \multicolumn{4}{|c|}{ Females } \\
\hline & $F$ & $p$ & $\eta^{2}$ & Pairwise & $F$ & $p$ & $\eta^{2}$ & Pairwise \\
\hline \multicolumn{9}{|l|}{ Start } \\
\hline 15-m time [\%] & 15.57 & $<0.001$ & 0.64 & $\begin{array}{l}\text { * (except Back vs } \\
\text { Free, Breast vs } \\
\text { Fly) }\end{array}$ & 10.67 & $<0.001$ & 0.53 & $\begin{array}{l}\text { * (except Back vs } \\
\text { Free, Breast vs } \\
\text { Fly) }\end{array}$ \\
\hline $\begin{array}{l}\text { Reaction time } \\
\text { [\%] }\end{array}$ & 34.05 & $<0.001$ & 0.78 & $\begin{array}{l}\text { * (except Back vs } \\
\text { Breast) }\end{array}$ & 28.86 & $<0.002$ & 0.75 & $\begin{array}{l}\text { * (except Back vs } \\
\text { Breast) }\end{array}$ \\
\hline Entry time [\%] & 63.80 & $<0.001$ & 0.87 & $\begin{array}{l}\text { * (except Free vs } \\
\text { Fly) }\end{array}$ & 61.31 & $<0.001$ & 0.86 & $\begin{array}{l}\text { * (except Free vs } \\
\text { Fly) }\end{array}$ \\
\hline Flight time [\%] & 19.54 & $<0.001$ & 0.67 & $\begin{array}{l}\text { * (except Free } \\
\text { vs Fly, Free vs } \\
\text { Breast, Fly vs } \\
\text { Breast) }\end{array}$ & 29.78 & $<0.001$ & 0.76 & $\begin{array}{l}\text { * (except Breast vs } \\
\text { Fly, Breast vs Free, } \\
\text { Fly vs Free) }\end{array}$ \\
\hline $\begin{array}{l}\text { Entry distance } \\
{[\%]}\end{array}$ & n. a. & n. a. & n. a. & & n. a. & n. a. & n. a. & \\
\hline $\begin{array}{l}\text { Underwater } \\
\text { time [\%] }\end{array}$ & 15.50 & $<0.001$ & 0.62 & $\begin{array}{l}\text { * (except Breast } \\
\text { vs Fly, Breast vs } \\
\text { Back) }\end{array}$ & 7.50 & 0.001 & 0.44 & $\begin{array}{l}\text { * (except Breast vs } \\
\text { Fly, Breast vs Free, } \\
\text { Fly vs Free) }\end{array}$ \\
\hline $\begin{array}{l}\text { Underwater } \\
\text { distance [\%] }\end{array}$ & n. a. & n. a. & n. a. & & n. a. & n. a. & n. a. & \\
\hline $\begin{array}{l}\text { Water break- } \\
\text { out time [\%] }\end{array}$ & 9.17 & $<0.001$ & 0.49 & $\begin{array}{l}\text { * (except Back vs } \\
\text { Breast, Back vs } \\
\text { Fly, Breast vs Fly) }\end{array}$ & 5.08 & 0.006 & 0.35 & $\begin{array}{l}\text { * (except Fly with } \\
\text { all, Free vs Breast) }\end{array}$ \\
\hline $\begin{array}{l}\text { Water break- } \\
\text { out distance } \\
{[\%]}\end{array}$ & n. a. & n. a. & n. a. & & n. a. & n. a. & n. a. & \\
\hline \multicolumn{9}{|l|}{ Turn } \\
\hline Total turn [\%] & 15.66 & $<0.001$ & 0.62 & $\begin{array}{l}\text { * (except Back vs } \\
\text { Free, Breast vs } \\
\text { Fly, Breast vs } \\
\text { Free) }\end{array}$ & 33.70 & $<0.001$ & 0.78 & $\begin{array}{l}\text { * (Breast vs Fly, } \\
\text { Breast vs Free) }\end{array}$ \\
\hline 5-m in [\%] & 41.59 & $<0.001$ & 0.81 & $\begin{array}{l}\text { * (except Back vs } \\
\text { Free) }\end{array}$ & 14.76 & $<0.001$ & 0.61 & $\begin{array}{r}\text { * (Back vs Free, } \\
\text { Breast vs Fly) }\end{array}$ \\
\hline $\begin{array}{l}\text { Water break- } \\
\text { out distance } \\
{[\%]}\end{array}$ & n. a. & n. a. & n. a. & & n. a. & n. a. & n. a. & \\
\hline $\begin{array}{l}\text { Water break- } \\
\text { out time [\%] }\end{array}$ & 10.98 & $<0.001$ & 0.54 & $\begin{array}{l}\text { * (except Back vs } \\
\text { Breast, Back vs } \\
\text { Fly, Breast vs Fly) }\end{array}$ & 12.48 & $<0.001$ & 0.57 & $\begin{array}{l}\text { * (except Back vs } \\
\text { Breast, Back vs } \\
\text { Fly, Breast vs Fly) }\end{array}$ \\
\hline $15-m$ out [\%] & 37.92 & $<0.001$ & 0.80 & $\begin{array}{l}\text { * (except Back vs } \\
\text { Free, Breast vs } \\
\text { Fly) }\end{array}$ & 53.16 & $<0.001$ & 0.85 & $*$ \\
\hline \multicolumn{9}{|l|}{ Start + Turn } \\
\hline $\begin{array}{l}\text { 15-m time + } \\
\text { total turn } \\
{[\%]}\end{array}$ & 2.53 & $p=0.079$ & 0.22 & $\#$ & 3.28 & 0.040 & 0.25 & $\begin{array}{l}\text { \# (except Free vs } \\
\text { Back) }\end{array}$ \\
\hline
\end{tabular}

Notes: Free-Freestyle; Fly—Butterfly; Back—Backstroke; Breast-Breaststroke.

* _ significant differences between all four swimming strokes $(p<0.05)$; \#—non-significant differences between all four swimming strokes $(p \geq 0.05)$.

The partial contribution in males ranged between $4.76 \pm 0.24 \%$ (95CI: 4.60;4.92) for the $5-\mathrm{m}$ and $15.20 \pm 0.30 \%$ (95CI: 14.92;15.49) for the $15-\mathrm{m}$ out in Breaststroke. In female swimmers, it ranged between $4.80 \pm 0.96 \%$ (95CI: 4.14;5.48) for the water break time in Freestyle and $15.41 \pm 0.26 \%$ (95CI: 15.18;15.66) for the $15-\mathrm{m}$ out in Butterfly. 


\section{Contribution of start plus turn to final race time}

The start time plus total turn time showed a significant and strong effect in the final race time (males: $F=155.82 ; p<0.001 ; \eta^{2}=0.94$; females: $F=94.32 ; p<0.001 ; \eta^{2}=0.90$ ). For both male and female swimmers, the pairwise comparison showed significant differences between all four swimming strokes (except for the females between Backstroke vs. Butterfly) (males: $1.88 \leq d \leq 11.03,0.006 \leq p<0.001$; females: $2.06 \leq d \leq 7.36, p \leq 0.001$ ). As noted earlier, the sum of starting and turning performances effects is dependent on the event to be swam.

The contribution effect showed non-significant (with minimum variations) between the swimming strokes (Table 4). The contribution was higher in the Freestyle event for both sexes (males: $31.69 \pm 0.37 \%$, 95CI: 28.22;35.15; females: $32.10 \pm 0.42 \%$, 95CI: 28,63;35.56) (Table 2); whereas, the lower was also in Backstroke for both sexes (males: $31.01 \pm 0.38 \%$, 95CI: 27.54;34.47; females: $31.41 \pm 0.48 \%$, 95CI: 27.94;34.87) (Table 2). This points out that, despite the swim event, the contribution of the start plus the turn is still a key-factor.

\section{Discussion and Implications}

The main aim of this study was to examine the starting and turning performances of elite swimmers, racing the final of the 100 -m events at a major swimming competition. There was an overall significant stroke effect in the starting and turning performances in both male and female swimmers. The start and the turn phases combined accounted for $31-32 \%$ of the final race time, and non-significant differences were observed between swimming strokes.

\section{Starting performance}

A stroke effect was noted in both sexes in the final race time, starting and turning performances. One can find a solid body of knowledge on the differences in the final race time between swimming strokes (e.g., Arellano et al., 1994; Chatard, Girold, Caudal, Cossor \& Mason, 2003; Jesus et al., 2011; Wakayoshi et al., 1992). However, evidence on differences in start and turning performances in the four events are scarce (e.g., Mason \& Cossor, 2001; Veiga \& Roig, 2016; Veiga et al., 2016). All start parameters showed a significant and moderate-strong stroke effect in both sexes. Regarding the start main outcome (15-m time), male swimmers were faster in the Butterfly event, followed-up by Freestyle, Backstroke and Breaststroke, respectively. Their female counterparts were faster in Freestyle, followed-up by Butterfly, Backstroke and Breaststroke, respectively. Overall, all strokes (i.e., pairwise comparison) showed significant differences in both males $(p<0.001)$ and females $(0.001<p<0.022)$ in the 15 -m time. The only non-significant differences $(p>0.05)$ were noted between Butterfly and Freestyle, in both sexes (Table 3 ). This points out that swimmers are prone to adopt a specific strategy to deliver the best race time, according to the event swam. Both sexes spent the shortest amount of time underwater in Freestyle (males: $2.59 \pm 0.72 \mathrm{~s}$; females: $3.07 \pm 0.62 \mathrm{~s}$ ), in comparison to Butterfly (males: $3.59 \pm 0.40 \mathrm{~s}$; females: $3.80 \pm 0.60 \mathrm{~s}$ ). The water breakout distance was farther in Butterfly (males: $12.53 \pm 1.98$ $\mathrm{m}$; females: $11.54 \pm 0.91-\mathrm{m}$ ) in comparison to Freestyle (males: $11.43 \pm 1.10-\mathrm{m}$; females: $10.74 \pm 1.07-\mathrm{m})$. This happens because of the ratio between the clean swim and underwater swim. Studies reported a faster clean speed in Freestyle (and Backstroke) (Arellano et al., 1994; Hellard et al., 2008). The underwater speed is similar in both strokes (since 
the underwater technique is the same for Freestyle and Butterfly). Therefore, swimmers choose to stay underwater while their underwater speed is higher (due to the wall pushoff) in comparison to the swim speed of the stroke being swam. In Freestyle, as the swim speed is higher than in Butterfly, swimmers choose to breakout sooner in this stroke (same rationality for Backstroke). In Butterfly events, they choose to optimise their underwater distance until almost the 15-m mark, because the swim speed is lower (Tor, Pease, \& Ball, 2014). In Breaststroke events, rules only allow to perform one full underwater stroke added to a dolphin kick. Breaststrokers, therefore, try to optimise the streamline glide and kicking. In Breaststroke swimmers perform two glides. One is a streamlined glide having the upper limbs together and stretched tightly overhead and a second glide keeping the upper limbs extended at the side of the trunk. Between these glides the swimmer performs an underwater arms' stroke. Studies reported differences in the passive drag gliding in the two different positions noted earlier (Marinho et al., 2009; Vilas-Boas et al., 2010). Because the Breaststroke start is restricted to one single underwater stroke, swimmers do try to optimise their underwater distance breakout by decreasing the passive drag (Marinho et al., 2009; Naemi, Easson, \& Sanders, 2010; Vilas-Boas et al., 2010) and/or enhancing the water entry (Tor et al., 2015). Overall, in the starting parameters, a significant stroke effect was observed, mostly between Backstroke and the remaining swimming strokes. These differences can be related to the specificity of the back start, that is the only where the swimmer starts in the water, reducing mostly the flight time, entry time and entry distance (Barkwell \& Dickey, 2017; de Jesus et al., 2013).

\section{Turning performance}

A significant and moderate-strong stroke effect was observed in the turning performance (Table 3). As in the total turn time (i.e., the main outcome), only the 15-m out presented a similar trend, being male and female swimmers faster in Freestyle, followed-up by Backstroke, Butterfly and Breaststroke, respectively (Table 1). Therefore, the 15-m out might be the key-parameter determining the overall turning performance. In Freestyle and Backstroke events, swimmers perform the flip turn. This turn is understood to be faster than the open turn used in Butterfly and Breaststroke events (Lyttle \& Mason, 1997). As in for the start, both male and female swimmers did breakout the water sooner in Freestyle (males: $7.76 \pm 1.88-\mathrm{m}$; females: $6.61 \pm 0.77-\mathrm{m}$ ), and as such resuming the swim stroke also sooner. These results are in tandem to reports by Veiga \& Roig $(2016,2017$; Veiga et al., 2016). Regarding Breaststroke, this is the swim stroke where swimmers (males and females) are slower at the 15-m out and show the shortest underwater breakout distance (except Freestyle in both sexes). Because of the rules constraints, swimmers are advised to adopt the most streamlined position as they can in this first gliding position (i.e., arms extended at the front) (Marinho, Barbosa, Rouboa, \& Silva, 2011; Vilas-Boas et al., 2010).

\section{Contribution of start plus turn to final race time}

Adding up the start and turn, male and female swimmers spent less time performing the start plus turn combined in Freestyle, and more time in Breaststroke (order for males: Freestyle, Backstroke, Butterfly and Breaststroke; order for females: Freestyle, Butterfly, Backstroke and Breaststroke) (Table 1). Overall, for both sexes, the starting performance 
(15-m time) accounts with $11-12 \%$ of the final race time, whereas the turning $19-20 \%$. Hence, the start and the turn combined account to a total of $31-32 \%$ of the time (i.e., nearly one third of a 100-m race time). Studies reported the parameters that swimmers should consider to enhance their on-block (Fischer \& Kibele, 2016; Tor et al., 2015; Vantorre et al., 2010) and in-water back start (de Jesus et al., 2013; Takeda, Itoi, Takagi, \& Tsubakimoto, 2014). The time at the 15 -m mark (main outcome) depends significantly from the takeoff velocity, entry angle, underwater time and distance (Fischer \& Kibele, 2016; Vantorre, Chollet, \& Seifert, 2014). This is, from the block phase, flight phase and underwater phase. In the turn, the push-off time and peak force on the wall performing the flip turn (Lyttle et al., 1999), and the wall contact time (hands and feet) and a quick pull-out in the open turn (Tourny-Chollet, Chollet, Hogie, \& Papparodopoulos, 2002), are the key determinants. A significant and moderate-strong contribution effect (Table 4) was noted for the start and turn parameters. However, the contribution of the start plus the turn combined presented a similar effect in all four events (non-significant differences). Females showed a significant contribution effect between strokes $(p=0.043)$, but this was trivial $\left(\eta^{2}=0.25\right.$; significant differences were only noted between Freestyle and Backstroke). Altogether, Freestyle (males: 31.69\%; females: 32.10\%) and Butterfly (males: $31.28 \%$; females: $31.88 \%$ ) events presented the highest dependency from the start plus turn performances combined (Table 2 ). Therefore, it seems that the amount of time spent training starts and turns, especially in these two events, is of extreme importance.

Coaches should be advised to design and prescribe high-quality drills and training tasks to improve the start and turn performances. For instance, proposing analytical drills or, alternatively over a regular swim training set deliver cues on what are the key-aspects of the start and/or turn that the swimmer is expect to deliver (Veiga \& Roig, 2017). For example, noting that over the set the swimmer can only breakout after reaching a given distance, or performing a given number of dolphin kicks. The latter alternative allows a more holistic practice and some better understanding how different start/turn strategies may affect the swim stroke (e.g., arm stroke count, stroke cadence, etc.).

\section{Conclusion}

Altogether, in elite sprinters, start and turn performances play major roles in the final race performance, and can account up to one third of the final race time. The effect of the start and turn combined were similar in all four swimming strokes. Both male and female swimmers, adopt different start and turn strategies, depending on the event to be raced.

\section{Acknowledgments}

To LEN (Ligue Européenne de Natation) and Spiideo AB for providing the videos. We would like to thank the support of the University of Beira Interior and Santander Universities (Bolsa BIPD/ICIFCSH-Santander Universidades-UBI/2017).

\section{Disclosure statement}

No potential conflict of interest was reported by the authors. 


\section{Funding}

This work was supported by National Funds through FCT - Portuguese Foundation for Science and Technology [UID/DTP/04045/2013] - and the European Fund for regional development (FEDER) allocated by European Union through the COMPETE 2020 Programme [POCI-01-0145-FEDER-006969].

\section{References}

Arellano, R., Brown, P., Cappaert, J., \& Nelson, R. (1994). Analysis of 50, 100, and $200 \mathrm{~m}$ freestyle swimmers at the 1992 Olympic Games. Journal of Applied Biomechanics, 10, 189-199. doi:10.1123/ jab.10.2.189

Arellano, R., García, F., Gavilán, A., \& Pardillo, S. (1996). Temporal analysis of the starting technique in freestyle swimming. In J. M. C. S. Abrantes (Ed.), XIV international symposium on biomechanics in sports (pp. 289-292). Lisboa: Faculdade de Motricidade Humana da Universidade Técnica de Lisboa.

Barbosa, T. M., Bragada, J. A., Reis, V. M., Marinho, D. A., \& Silva, A. J. (2010). Energetics and biomechanics as determining factors of swimming performance: Updating the state of the art. Journal of Science and Medicine in Sport, 13, 262-269. doi:10.1016/j.jsams.2009.01.003

Barkwell, G. E., \& Dickey, J. P. (2017). Backstroke start performance: The impact of using the OmegaOBL2 backstroke ledge. Sports Biomechanics, Epub ahead of print.

Blanksby, B., Nicholson, L., \& Elliott, B. (2002). Biomechanical analysis of the grab, track and handle swimming starts: An intervention study. Sports Biomechanics, 1, 11-24. doi:10.1080/14763140208522784

Blanksby, B. A., Simpson, J. R., Elliott, B. C., \& McElroy, K. (1998). Biomechanical factors influencing breaststroke turns by age-group swimmers. Journal of Applied Biomechanics, 14, 180-189. doi:10.1123/jab.14.2.180

Chatard, J., Girold, S., Caudal, N., Cossor, J. M., \& Mason, B. (2003). Analysis of the $200 \mathrm{~m}$ events in the Sydney Olympic Games. In J. Chatard (Ed.), Biomechanics and medicine in swimming IX (pp. 261-264). Saint-Etienne: Université de Saint-Etienne.

Cohen, J. (1988). Statistical power analysis for the behavioral sciences. Hillsdale, NJ: Lawrence Earlbaum Associates.

Cossor, J. M., \& Mason, B. R. (2001). Swim start performances at the Sydney 2000 Olympic Games. In J. Blackwell \& R. H. Sanders (Eds.), Proceedings of swim sessions: XIX international symposium on biomechanics in sports (pp. 70-74). San Francisco, CA: International Society of Biomechanics in Sports.

Craig, A. B., \& Pendergast, D. R. (1979). Relationships of stroke rate, distance per stroke, and velocity in competitive swimming. Medicine and Science in Sports, 11, 278-283.

de Jesus, K., de Jesus, K., Figueiredo, P., Gonçalves, P., Pereira, S. M., Vilas-Boas, J. P., \& Fernandes, R. J. (2013). Backstroke start kinematic and kinetic changes due to different feet positioning. Journal of Sports Sciences, 31, 1665-1675. doi:10.1080/02640414.2013.794298

Ferguson, C. J. (2009). An effect size primer: A guide for clinicians and researchers. Professional Psychology: Research and Practice, 40, 532-538. doi:10.1037/a0015808

Fischer, S., \& Kibele, A. (2016). The biomechanical structure of swim start performance. Sports Biomechanics, 15, 397-408. doi:10.1080/14763141.2016.1171893

Guimarães, A. C., \& Hay, J. G. (1985). A mechanical analysis of the grab starting technique in swimming. International Journal of Sport Biomechanics, 1, 25-35. doi:10.1123/ijsb.1.1.25

Hellard, P., Dekerle, J., Avalos, M., Caudal, N., Knopp, M., \& Hausswirth, C. (2008). Kinematic measures and stroke rate variability in elite female $200-\mathrm{m}$ swimmers in the four swimming techniques: Athens 2004 Olympic semi-finalists and French National 2004 championship semifinalists. Journal of Sports Sciences, 26, 35-46. doi:10.1080/02640410701332515

Hubert, M., Silveira, G. A., Freitas, E., Pereira, S., \& Roesler, H. (2006). Speed variation analysis before and after the stroke in swimming starts. Biomechanics and Medicine in Swimming, 6, 44-45. 
Jesus, S., Costa, M. J., Marinho, D. A., Garrido, N., Silva, A. J., \& Barbosa, T. M. (2011). 13th FINA World Championship finals: Stroke kinematical and race times according to performance, gender and event. Portuguese Journal of Sport Sciences, 11, 275-278.

Lyttle, A. D., Blanksby, B. A., Elliott, B. C., \& Lloyd, D. G. (1999). Investigating kinetics in the freestyle flip turn push-off. Journal of Applied Biomechanics, 15, 242-252. doi:10.1123/jab.15.3.242

Lyttle, A. D., Blanksby, B. A., Elliott, B. C., \& Lloyd, D. G. (2000). Net forces during tethered simulation of underwater streamlined gliding and kicking techniques of the freestyle turn. Journal of Sports Sciences, 18, 801-807. doi:10.1080/026404100419856

Lyttle, A. D., \& Mason, B. A. (1997). Kinematic and kinetic analysis of the freestyle and butterfly turns. Journal of Swimming Research, 12, 7-11.

Marinho, D. A., Barbosa, T. M., Rouboa, A. I., \& Silva, A. J. (2011). The hydrodynamic study of the swimming gliding: A two-dimensional computational fluis dynamics (CFD) analysis. Journal of Human Kinetics, 29, 49-57.

Marinho, D. A., Reis, V. M., Alves, F. B., Vilas-Boas, J. P., Machado, L., Silva, A. J., \& Rouboa, A. (2009). Hydrodynamic drag during gliding in swimming. Journal of Applied Biomechanics, 25, 253-257. doi:10.1123/jab.25.3.253

Mason, B. R., \& Cossor, J. M. (2001). Swim turn performances at the Sydney 2000 Olympic Games. In J. Blackwell \& R. H. Sanders (Eds.), Proceedings of swim sessions: XIX international symposium on biomechanics in sports (pp. 65-69). San Francisco, CA: International Society of Biomechanics in Sports.

Naemi, R., Easson, W. J., \& Sanders, R. H. (2010). Hydrodynamic glide efficiency in swimming. Journal of Science and Medicine in Sport, 13, 444-451. doi:10.1016/j.jsams.2009.04.009

Pereira, S. M., Ruschel, C., Hubert, M., Machado, L., Roesler, H., Fernandes, R. J., \& Vilas-Boas, J. P. (2015). Kinematic, kinetic and EMG analysis of four front crawl flip turn techniques. Journal of Sports Sciences, 33, 2006-2015. doi:10.1080/02640414.2015.1026374

Ruschel, C., Araùjo, L., Pereira, S., \& Roesler, H. (2007). Kinematical analysis of the swimming start: Block, flight and underwater phases. International Society of Biomechanics in Swimming Conference Proceedings, 385-388.

Slawson, S., Conway, P., Jusham, L., Le Sage, T., \& West, A. (2010). Dynamic signature for tumble turn performance in swimming. Procedia Engineering, 2, 3391-3396. doi:10.1016/j.proeng.2010.04.163

Takeda, T., Itoi, O., Takagi, H., \& Tsubakimoto, S. (2014). Kinematic analysis of the backstroke start: Differences between backstroke specialists and non-specialists. Journal of Sports Sciences, 32, 635-641. doi:10.1080/02640414.2013.845678

Tor, E., Pease, D. L., \& Ball, K. A. (2014). Characteristics of an elite swimming start. In B. Mason (Ed.), XIIth international symposium for biomechanics and medicine in swimming (pp. 257-263). Canberra: Canberra Australian Institute of Sport.

Tourny-Chollet, C., Chollet, D., Hogie, S., \& Papparodopoulos, C. (2002). Kinematic analysis of butterfly turns of international and national swimmers. Journal of Sports Sciences, 20, 383-390. $10.1080 / 026404102317366636$

Tor, E., Pease, D. L., \& Ball, K. A. (2015). Key parameters of the swimming start and their relationship to start performance. Journal of Sports Sciences, 33, 1313-1321. doi:10.1080/02640414.2014.990486

Vantorre, J., Seifert, L., Fernandes, R. J., Vilas-Boas, J. P., \& Chollet, D. (2010). Kinematical profiling of the front crawl start. International Journal of Sports Medicine, 31, 16-21. doi:10.1055/s-0029-1241208

Vantorre, J., Chollet, D., \& Seifert, L. (2014). Biomechanical analysis of the swim-start: A review. Journal of Sports and Science in Medicine, 13, 223-231.

Veiga, S., \& Roig, A. (2016). Underwater and surface strategies of $200 \mathrm{~m}$ world level swimmers. Journal of Sports Sciences, 34, 766-771. doi:10.1080/02640414.2015.1069382

Veiga, S., \& Roig, A. (2017). Effect of the starting and turning performances on the subsequent swimming parameters of elite swimmers. Sports Biomechanics, 16, 34-44. doi:10.1080/1476314 1.2016.1179782

Veiga, S., Roig, A., \& Gómez-Ruano, M. A. (2016). Do faster swimmers spend longer underwater than slower swimmers at World Championships? European Journal of Sport Science, 16, 919-926. doi:10.1080/17461391.2016.1153727 
Vilas-Boas, J. P., Costa, L., Fernandes, R. J., Ribeiro, J., Figueiredo, P., Marinho, D. A., .. Machado, L. (2010). Determination of the drag coefficient during the first and second gliding positions of the breaststroke underwater stroke. Journal of Applied Biomechanics, 26, 324-331. doi:10.1123/ jab.26.3.324

Wakayoshi, K., Nomura, T., Takahashi, G., Mutoh, Y., \& Miyashita, M. (1992). Analysis of swimming races in the 1989 Pan Pacific Swimming Championships and 1988 Japanese Olympic trials. In D. Maclaren, T. Reilly, \& A. Less (Eds.), Biomechanics and medicine in swimming: Swimming science (VI) (pp. 135-142). London: Spon Press. 